\title{
Anatomical variations in the left coronary artery and its branches
}

Mamatha Hosapatna ${ }^{1}$, MBBS, MD, Antony Sylvan D'Souza $^{1}$, MBBS, MS, Lokadolalu Chandracharya Prasanna ${ }^{1}$, MBBS, MD, Vijayalakshmi Sitanadhi Bhojaraja ${ }^{1}$, MBBS, Suhani $\underline{\text { Sumalatha }}^{1}$, BAMS, MSc

INTRODUCTION Proficiency in the anatomy of coronary arteries and their variations is important for proper interpretation of coronary angiographies. The left coronary artery (LCA) commonly originates at the level of the left posterior aortic sinus and normally bifurcates into the anterior interventricular artery and circumflex artery. This study aimed to determine the variations in the LCA and its branches.

METHODS The study was conducted on 30 heart specimens. We observed the origin, length and branching pattern of the LCA and its coronary dominance.

RESULTS We found a short main LCA trunk in three specimens and a long main LCA trunk in one specimen. In two specimens, the division of the LCA led to three branches. With regard to 'dominance', one specimen showed left dominance while another showed codominance.

CONCLUSION Variations of the LCA are clinically relevant, especially when a perioperative coronary perfusion or coronary arteriography is performed.

Keywords: angiography, coronary artery, dominance, variations, vessels

Singapore Med J 2013; 54(1): 49-52

\section{INTRODUCTION}

The coronary arteries are the first vessels that branch from the aorta, normally originating below the junction between the bulbus and the ascending aorta, i.e. at the sinotubular junction. The right and left coronary arteries (RCA and LCA, respectively) arise from the ascending aorta. Patency of the LCA is vital for sufficient perfusion of most of the heart. The LCA is responsible for irrigation of most of the left ventricle and also a considerable proportion of the right ventricle. ${ }^{(1)}$

The LCA arises from the left posterior aortic sinus. Its length is variable, although it is not usually more than a few millimetres. It lies between the pulmonary trunk and the left atrial auricle, emerging into the atrioventricular (AV) groove, in which it turns left. Reaching the AV groove, the LCA usually divides into two main branches: the anterior interventricular artery (AIVA) and the circumflex artery $(\mathrm{CA}) .^{(2)}$ The AIVA (left anterior descending artery) passes to the left of the pulmonary trunk, travels into the upper portion of the interventricular sulcus and continues toward the apex of the heart. It branches into the anterior ventricular rami (diagonal artery) and septal rami. ${ }^{(3)}$ The CA arises from the left main artery at almost a right angle. Its course nearly mirrors that of the $\mathrm{RCA}$, as it travels under the left atrial appendage in the left AV sulcus around the left acute margin and toward the crux in most hearts, but sometimes it continues as a posterior interventricular artery (PIVA). The CA typically branches into the sinoatrial nodal artery, left marginal artery, and the atrial and ventricular rami. ${ }^{(3)}$ The term 'dominant' is used to refer to the coronary artery giving off the PIVA, which supplies the posterior part of the ventricular septum, and often, to a part of the posterolateral wall of the left ventricle. The RCA is usually the dominant artery (60\%). Left dominance is when the PIVA arises from the circumflex branch of the LCA. ${ }^{(2)}$

Proficiency in the anatomy of coronary arteries and their variations is vital for proper interpretation of coronary angiographies, as well as for the assessment of complexities and results of coronary insufficiency and surgical myocardium revascularisation. The LCA presents wide variability in its morphological expression. Thus, this study aimed to determine these variations in the LCA and its branches.

\section{METHODS}

The study was conducted on 30 heart specimens that were used during routine dissection for medical undergraduates in the Department of Anatomy, Kasturba Medical College, Manipal, India. We observed the origin, length and branching pattern of the LCA and its coronary dominance. The length of the LCA was measured using a digital vernier calliper.

\section{RESULTS}

In all the heart specimens (the approximate age was 50-80 years in both genders), the LCA originated normally, i.e. from the left posterior aortic sinus. No other associated variations or anomalies were found during dissection. Applying the criteria of extreme values, ${ }^{(1,4,5)}$ we found a short main LCA trunk in three out of the $30(10 \%)$ specimens and a long main LCA trunk in one (3.3\%) specimen (Fig. 1). The length of the LCA trunk in the rest of the specimens $(86.7 \%)$ was between $6-15 \mathrm{~mm}$. The mean length of the LCA trunks was $8.86 \pm 2.96 \mathrm{~mm}$.

The most frequent type of division was a bifurcation into two terminal branches (28/30; 93.3\%) - the AIVA and CA. 


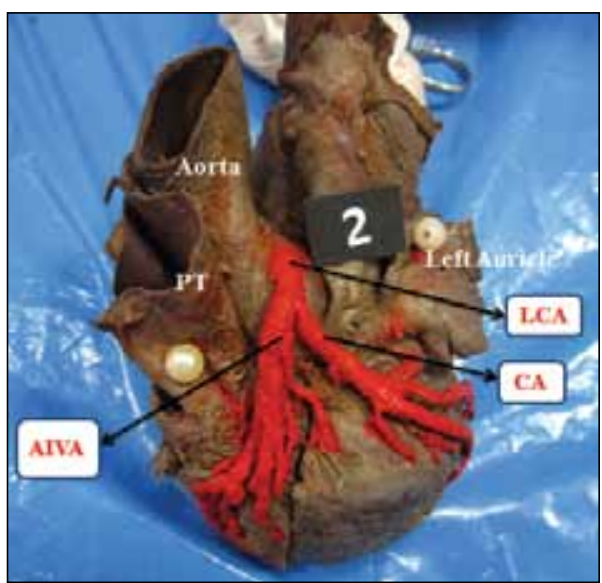

Fig. 1 Photograph of the specimen shows a long main LCA trunk. LCA: left coronary artery; CA: circumflex artery; AIVA: anterior interventricular artery; PT: pulmonary trunk

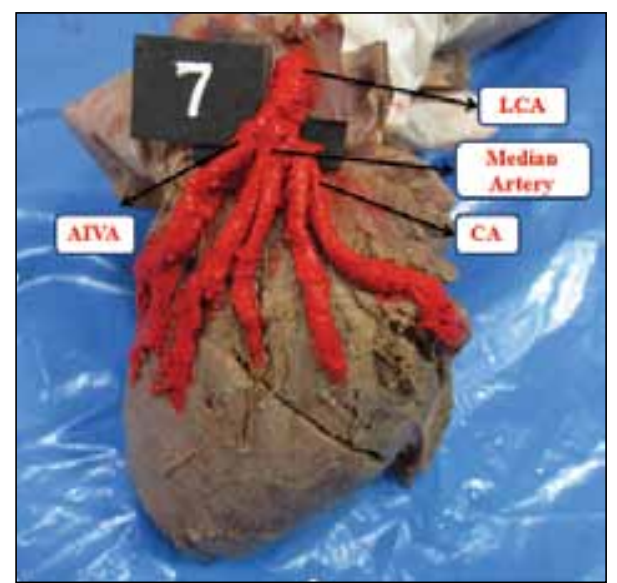

Fig. 2 Photograph of the specimen shows three divisions emanating from the LCA. LCA: Ieft coronary artery; CA: circumflex artery; AIVA: anterior interventricular artery
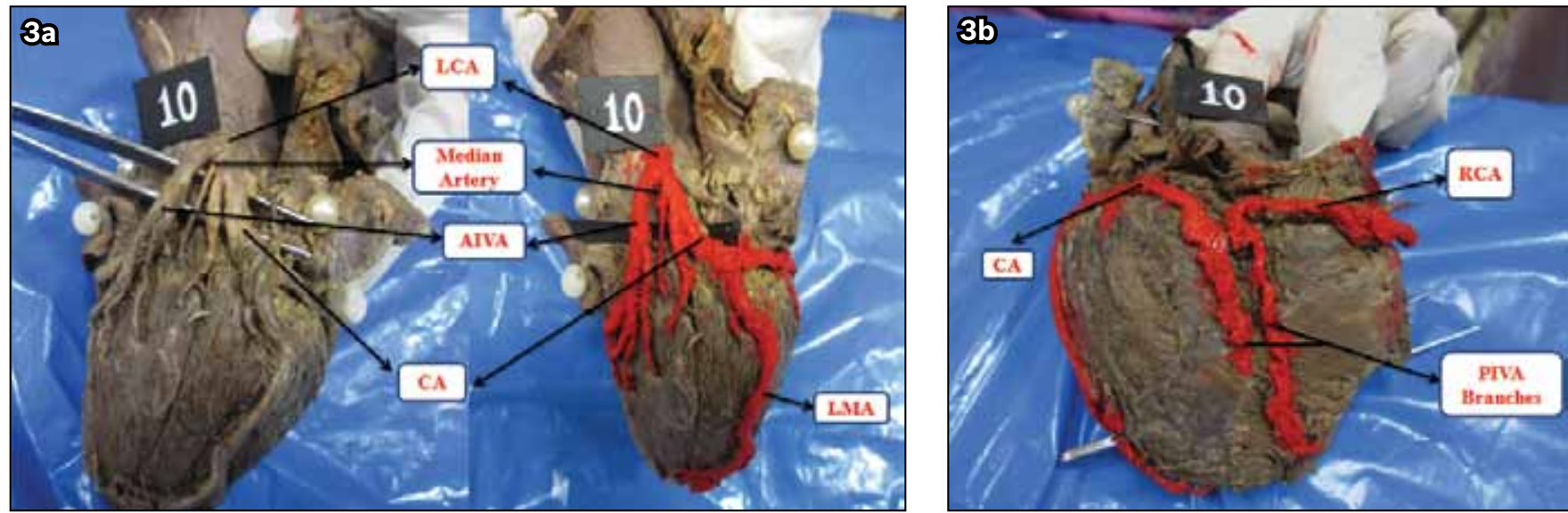

Fig. 3 Photographs of the specimen show (a) three or more branches from the main LCA trunk; and (b) two PIVA, one each from the CA and RCA. LCA: left coronary artery; AIVA: anterior interventricular artery; CA: circumflex artery; LMA: left marginal artery; RCA: right coronary artery; PIVA: posterior interventricular artery

We did not observe any variations in the angle of bifurcation of the artery. In two out of the 30 specimens $(6.7 \%$, Specimens 7 \& 10), the division of the LCA led to three branches (Figs. 2 \& 3a). These complementary branches are known as intermediate or median arteries (MAs). In Specimen 7, the MA ran parallel to the AIVA and gave off a diagonal branch. In Specimen 10, the MA was small, thin and almost parallel to the AIVA. In all the heart specimens, the PIVA arose from the RCA, indicating right dominance, except in Specimen 6 (Fig. 4), where the PIVA arose from the circumflex branch of the LCA, indicating left dominance. In Specimen 10 (Fig. 3b), the posterior interventricular septum was supplied by both the LCA and RCA, indicating codominance.

\section{DISCUSSION}

The LCA is the main source of blood supply to the heart. ${ }^{(1,6)}$ Kalbfleisch and Hort, who conducted a study on the area irrigated by each of the coronary arteries using postmortem angiography, showed that the LCA irrigated $68.8 \%$ of the cardiac muscle mass (AIVA: $41.5 \%$; CA: $27.3 \%$ ) and $79 \%$ of the left ventricular cardiac muscle mass (AIVA: 52.6\%; CA: 26.4\%). ${ }^{(7)}$ Hence, obstructive disease of the LCA may reduce the coronary flow to a large proportion of the ventricular myocardium, and as

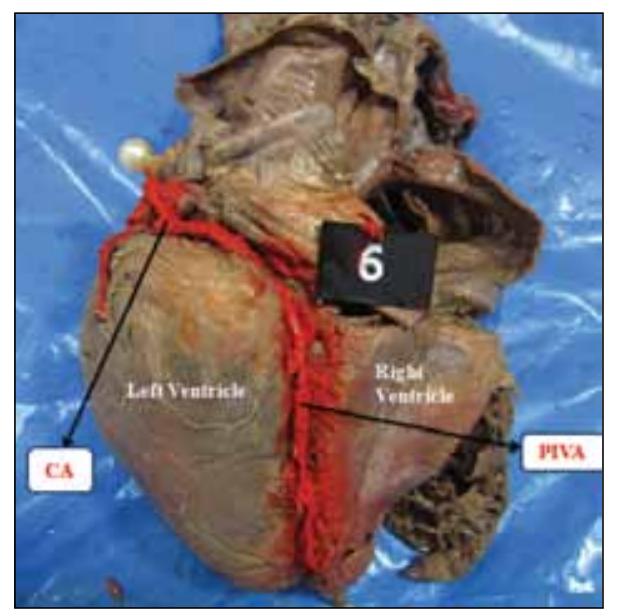

Fig. 4 Photograph of the specimen shows the PIVA arising from the right coronary artery. CA: circumflex artery; PIVA: posterior interventricular artery

a result, atherosclerotic diseases of the LCA have more serious complications than those of the RCA.(1)

The length of the LCA trunk is generally about 5-15 mm long. ${ }^{(1)}$ Short and long LCA trunks were therefore considered to be variants in the length. ${ }^{(8)}$ Fox et al reported that the LCA trunk in $73 \%$ of their cases was $\leq 6 \mathrm{~mm}$ in length. ${ }^{(9)}$ Banchi observed that the length of the LCA trunk was $<5 \mathrm{~mm}$ in $2 \%$ of specimens, ${ }^{(10)}$ 
Table I. Comparison of studies on length and branching pattern of the trunk of the left coronary artery.

\begin{tabular}{|c|c|c|c|c|}
\hline Study (yr) & No. of specimens & Method & Length $(\mathrm{mm}) ; \%$ of specimens & No. of branches; \% of specimens \\
\hline $\begin{array}{l}\text { Banchi } \\
(1904)^{(10)}\end{array}$ & 100 & Dissection & $\begin{array}{l}<5 ; 2 \% \\
5-10 ; 87 \% \\
>10 ; 11 \%\end{array}$ & $\begin{array}{l}2 ; 64 \% \\
3 ; 31 \% \\
4 ; 5 \%\end{array}$ \\
\hline $\begin{array}{l}\text { Bosco } \\
(1935)^{(15)}\end{array}$ & 135 & Dissection & SD: 10 & $\begin{array}{l}0 ; 2 \% \\
2 ; 42 \% \\
3 ; 55 \%\end{array}$ \\
\hline $\begin{array}{l}\text { Gazetopoulos } \\
(1976)^{(12)}\end{array}$ & 204 & Dissection & SD: 11.02 & NS \\
\hline $\begin{array}{l}\text { Green } \\
(1967)^{(14)}\end{array}$ & 50 & Dissection & SD: 11.6 & NS \\
\hline $\begin{array}{l}\text { Hadziselimović } \\
(1982)^{(16)}\end{array}$ & 100 & Dissection & NS & $\begin{array}{l}2 ; 52 \% \\
3 ; 44 \% \\
>3 ; 4 \%\end{array}$ \\
\hline $\begin{array}{l}\text { McAlpine } \\
(1975)^{(4)}\end{array}$ & 100 & Dissection & $\begin{array}{l}<6 ; 12 \% \\
6-15 ; 74 \% \\
>15 ; 14 \%\end{array}$ & NS \\
\hline $\begin{array}{l}\text { Benther } \\
(1976)^{(17)}\end{array}$ & 125 & Dissection & SD: 11 & $\begin{array}{l}0 ; 2 \% \\
2 ; 89 \% \\
3 ; 9 \%\end{array}$ \\
\hline $\begin{array}{l}\text { Reig and Petit } \\
(2004)^{(1)}\end{array}$ & 95 & Dissection & $\begin{array}{l}\text { Mean: } 10.8 \\
\leq 5 ; 7.4 \% \\
5-15 ; 73.7 \% \\
>15 ; 18.9 \%\end{array}$ & $\begin{array}{l}2 ; 62 \% \\
>3 ; 38 \%\end{array}$ \\
\hline $\begin{array}{l}\text { Candir } \\
(2010)^{(6)}\end{array}$ & 77 & Coronary angiography & $\begin{array}{l}<5 ; 6.5 \% \\
5-15 ; 50.65 \% \\
>15 ; 42.85 \%\end{array}$ & NS \\
\hline Present study & 30 & Dissection & $\begin{array}{l}\text { Mean } \pm \text { SD: } 8.86 \pm 2.96 \\
\leq 5 ; 10 \% \\
6-15 ; 86.7 \% \\
>15 ; 3.3 \%\end{array}$ & $\begin{array}{l}2 ; 93.3 \% \\
3 ; 6.7 \%\end{array}$ \\
\hline
\end{tabular}

NS: not specified; SD: standard deviation

while Reig et al reported that $7.4 \%$ of their specimens had an LCA trunk length of $<5 \mathrm{~mm} .{ }^{(11)} 12 \%$ of specimens had a short LCA trunk $(<6 \mathrm{~mm})$ in McAlpine's study. ${ }^{(4)}$ Only $10 \%$ of the specimens in our series presented with a LCA trunk length $\leq 5 \mathrm{~mm}$.

A short main LCA trunk has been considered a risk factor for the development of coronary arteriosclerosis. ${ }^{(12,13)}$ This is because during systole, a certain degree of twisting of the terminal branches, which increases the mechanical effort undergone by its walls, leads to greater arteriosclerotic degeneration. A short LCA trunk is also considered a risk factor for coronary perfusion during surgical operation, such as during replacement of the aortic valves. In such situations, the catheter may be inserted into one of the terminal branches, leading to ischaemia in the territory of the terminal branch, which may cause ventricular arrhythmia, myocardial infarction, or both. ${ }^{(5)}$ Furthermore, a short trunk length may also cause difficulty when carrying out coronary angiography because when the catheter is inserted into one of the terminal branches, opacification of the other branch does not occur and an incomplete image of the coronary tree is seen.

A long main LCA trunk (> $15 \mathrm{~mm}$ ) has been reported in several studies. $26 \%$ of the specimens in Green et al's study, ${ }_{1}^{(14)} 14 \%$ in McAlpine's, ${ }^{(4)} 11 \%$ in Banchi's, ${ }^{(10)}$ and 3.3\% in the current study had a long main LCA trunk measuring $>15 \mathrm{~mm}$. No relationship has been described between a long main LCA trunk and any type of pathology or technical complications.
The branching pattern of the LCA has been extensively described in the literature. Banchi described the termination of between two to three branches, with the most common (64\%) being bifurcation of the LCA main trunk into its terminal branches - the AIVA and CA. The possibility of the main LCA trunk dividing into three or four branches (31\% and $5 \%$, respectively) was also mentioned in the same study. ${ }^{(10)}$ Bosco observed that in $2 \%$ of the specimens, there was no division of the main LCA trunk, while $42 \%$ of the specimens had bifurcation and $55 \%$ had trifurcation. ${ }^{(15)}$ Hadziselimović reported that out of the $52 \%$ of cases with bifurcation in the series, $44 \%$ had trifurcation and only $4 \%$ had more than three branches. ${ }^{(16)}$ Benther et al observed $2 \%$ of specimens with no division of the trunk, $89 \%$ with bifurcation and $9 \%$ with trifurcation. ${ }^{(17)}$ A study by Reig and Petit found that $62 \%$ of specimens had bifurcation and $38 \%$ had more than three branches. ${ }^{(1)}$ In the present study, about $6.7 \%$ of the specimens $(n=2)$ had trifurcation of the main LCA trunk, while the remaining had bifurcation. Identification of the MA may be of clinical importance; although its area of distribution is usually small, the MA irrigates areas that, in the absence of trifurcation of the LCA, are irrigated by the AIVA and CA, and thus, its existence may decrease the effect of occlusion of these arteries. ${ }^{(11)}$ The published data from different studies show a certain degree of disparity in results, depending on the technique used by the authors. A comparison of the various studies is shown in Table I. 
With regard to the dominance of the coronary arteries, a minority of the population may have left coronary predominance when the PIVA extends as a continuation of the LCA. These individuals are likely to be affected by coronary diseases, as the entire left ventricle and the ventricular septum are under the nutritional control of the LCA, and obstruction of the latter may cause output failure of systemic circulation. On rare occasions, the PIVA is derived from both the coronary arteries, and individuals with such a codominant pattern of coronary distribution are the least affected by coronary diseases. ${ }^{(18)}$

In conclusion, with the current widespread use of new diagnostic imaging techniques and the development of nonaggressive treatments, thorough knowledge of normal coronary anatomy and its variations is essential. Failure to distinguish between normal and anomalous structures may lead to misinterpretations and disastrous complications during heart surgery.

\section{REFERENCES}

1. Reig J, Petit M. Main trunk of the left coronary artery: anatomic study of the parameters of clinical interest. Clin Anat 2004; 17:6-13.

2. Gatzoulis MA. Heart and great vessels. In: Standring S, ed. Gray's Anatomy: The Anatomical Basis of Clinical Practice. 40th ed. Philadelphia: Churchill Livingstone (Elsevier), 2008: 978-80.

3. Fiss DM. Normal coronary anatomy and anatomic variations. Appl Radiology 2007 (Suppl); 14-26.

4. McAlpine WA, ed. Heart and Coronary Arteries: An Anatomical Atlas for Clinical Diagnosis, Radiological Investigation, and Surgical Treatment. Berlin: Springer-Verlag, 1975: 133-50.
5. Vlodaver Z, ed. Coronary Heart disease: Clinical, Angiographic and Pathologic Profiles. New York: Springer-Verlag, 1976: 177-88.

6. Çandir N, Ozan H, Kocabiyik N, Kuşakligil H. Anatomical risk factors of coronary heart disease. Balkan Med J 2010; 27:248-52.

7. Kalbfleisch H, Hort W. Quantitative study on the size of coronary artery supplying areas postmortem. Am Heart J 1977; 94:183-8.

8. Angelini P, Villason S, Chan AV Jr, Diez JG. Normal and anomalous coronary arteries in humans. In: Angelini P, ed. Coronary Artery Anomalies: A Comprehensive Approach. Philadelphia: Lippincott Williams \& Wilkins, 1999: 27-150

9. Fox C, Davies MJ, Webb-Peploe MM. Length of left main coronary artery. Br Heart J 1973; 35:796-8.

10. Banchi A. Morfologia delle arteriae coronariae cordis. Arch Ital Anat Embriol 1904; 3:7-164.

11. Reig J, Jornet A, Petit M. Anatomical variations of the coronary perfusion as a basis of myocardial vulnerability to coronary artery occlusion. Clin Anat 1994; 7:315-23.

12. Gazetopoulos N, loannidis PJ, Karydis C, et al. Short left coronary artery trunk as risk factor in the development of coronary atherosclerosis. Pathological study. Br Heart J 1976; 38:1160-5.

13. Gazetopoulos N, loannidis PJ, Marselos A, et al. Length of main left coronary artery in relation to atherosclerosis of its branches. A coronary arteriographic study. Br Heart J 1976; 38:180-5.

14. Green GE, Bernstein S, Reppert EH. The length of the left main coronary artery. Surgery $1967 ; 62: 1021-4$

15. Bosco GA. Diagnóstico anátomo-topográfico de la obstrucción arterial coronaria. Buenos Aires: Artes Gráficas Modernas, 1935: 27-30.

16. Hadziselimović H. Blood vessels of the human heart. Leipzig: Thieme, 1982: 14-20.

17. Benther P, Barra JA, Blanc JJ. [Descriptive anatomical study of the major coronary trunks and the principal epicardial collaterals. 125 cases]. Nouv Presse Med, 1976; 5:71-5. French.

18. Datta AK. Essentials of Human Embryology. 5th ed. Kolkata: Current Books International, 2005: 71-2.

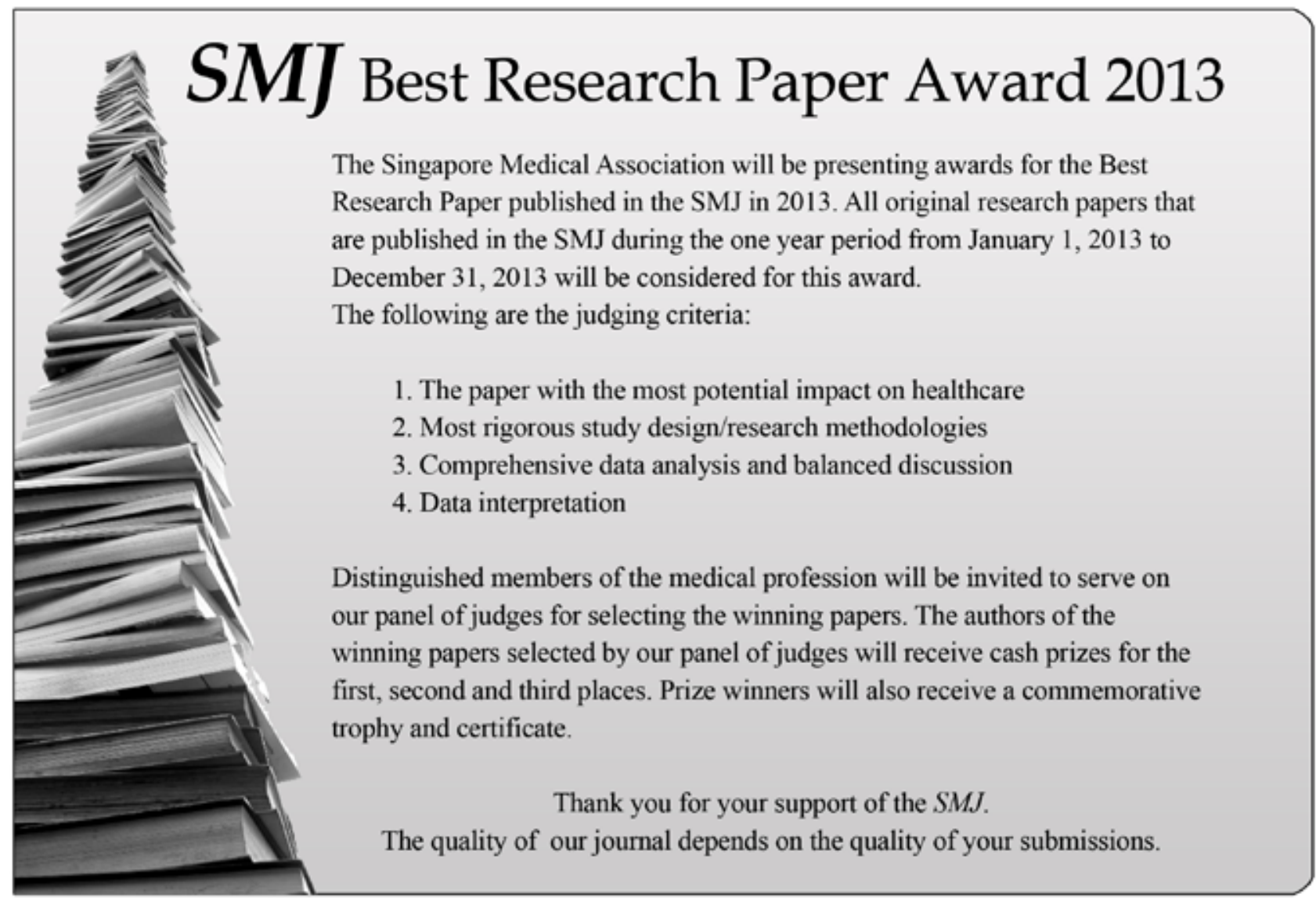

